\title{
A perspectiva dos alunos de escolas "tradicionais" sobre educação ambiental: um estudo de caso de escolas da cidade de Fortaleza/CE
}

\author{
The perspective of "traditional" school students on environmental \\ education: a case study of schools in the city of Fortaleza/CE
}

\section{Genaro Alves da Silva Neto ${ }^{1}$ José Werlon Ferreira de Souza ${ }^{2}$ Leonor de Maria Rodrigues Melo ${ }^{3}$}

\begin{abstract}
1 Acadêmico de Geografia. Universidade Estadual do Ceará. E-mail: genaroneto2014@gmail.com
2 Acadêmico de Geografia. Universidade Estadual do Ceará. E-mail: werlon.souza@aluno.uece.br

3 Mestra em Geografia. Universidade Estadual do Ceará. E-mail: leonordemaria.melo@uece.br
\end{abstract}

RESUMO: A Educação Ambiental surge como possibilidade de informar pessoas sobre condições e problemáticas ambientais mundiais. A regulamentação do ensino dessa temática na escola abre a perspectivas de desenvolver nos estudantes a capacidade de compreender e refletir sobre as questões ambientais. O presente trabalho buscou entender a perspectiva dos alunos de escolas "tradicionais" sobre a disciplina. Tendo como procedimentos: levantamento bibliográfico, documental e pesquisa de campo e como método, o estudo de caso. As informações colhidas constataram que o acesso dos discentes a temática são: livros, Internet, Jornais/revistas, Escola, Televisão e Palestras, confirmando a baixa participação das escolas sobre o tema. Palavras chave: Estudo de caso. Ensino. Perspectiva ambiental.

ABSTRACT: Environmental Education appears as a possibility to inform people about global environmental conditions and problems. The regulation of the teaching of this subject in the school opens the perspectives to develop in the students the capacity to understand and to reflect on the environmental questions. The present work sought to understand the perspective of the students of "traditional" schools about the discipline. Having as procedures: bibliographical survey, documentary and field research and as method, the case study. The information gathered showed that the access of the students to the theme are: books, Internet, Newspapers / magazines, School, Television and Lectures, confirming the low participation of schools on the subject.

Keywords: Case study. Teaching. Environmental perspective.

Sumário: Introdução - 1 Arcabouço Teórico - 2 Percurso Metodológico - 3 Resultados e Discussões - Considerações Finais - Referências

\section{INTRODUÇÃO}

Diante dos eventos ocorridos, como o Grande Nevoeiro, em Londres, no 1952, que comprometeram o equilíbrio do meio ambiente, a educação ambiental (EA) aparece com a perspectiva de proporcionar a sociedade ações voltadas para a compreensão e a melhoria das condições ambientais. A partir da instituição da Política Nacional de Educação Ambiental (PNEA) em 1994, foi implantado a formação sobre as questões ambientais, de maneira formal nas escolas e informal nos meios de comunicação. Neste estudo, será retratada uma análise das principais características do ensino da temática ambiental nas escolas que se adequam a pedagogia tradicional de ensino, com base na EA conservadora. 
Este artigo se propõe a entender a perspectiva dos alunos de escolas tradicionais sobre a EA. Para se chegar a este propósito é necessário analisar como a EA deve se encaixar no currículo das escolas tradicionais, observar o nível de conhecimento dos docentes em geografia sobre as leis e parâmetros relacionados a EA e conhecer quais os principais veículos de informações dos alunos sobre a temática ambiental.

Ao construir está pesquisa, admite-se que entender a perspectiva dos alunos de escolas tradicionais sobre a EA é necessário e significativo para a sociedade e comunidade cientifica, visto que a EA tem como característica principal, possibilitar o entendimento e a informação dos cidadãos sobre as problemáticas, a partir do enfoque interdisciplinar e transversal, de modo integrado e contínuo, além do caráter participativo e dinâmico na construção do conhecimento, sendo importante conhecer o nível de compreensão dos estudantes do ensino fundamental II de duas escolas tidas como tradicionais sobre a temática ambiental.

Para a construção deste trabalho, foi utilizado o estudo de caso como método de pesquisa, sendo que na coleta dos dados foi aplicado a investigação qualitativa, visando a qualificação dos dados, se propondo a estudar a realidade, explicando as relações sociais. Os procedimentos metodológicos para a construção desta pesquisa foram pesquisa bibliográfica e a pesquisa documental, trabalho de campo, análise dos dados e a produção do trabalho.

O trabalho de campo foi realizado em duas escolas ${ }^{1}$, onde a primeira escola está localizada no bairro Conjunto Esperança, enquanto a segunda escola fica no bairro Bonsucesso, em Fortaleza, as duas em Fortaleza, no Estado do Ceará. A realização desta pesquisa teve o intuito de construir novas reflexões e mostrar a importância da EA sobre a perspectiva dos alunos, na construção da formação de cidadãos conscientes sobre as problemáticas ambientais e as alternativas para conservar o meio ambiente.

\section{ARCABOUÇO TEÓRICO}

A EA ao ganhar espaço e relevância no cenário nacional e mundial e tem inúmeros conceitos e finalidades da temática formuladas por diversos autores e órgãos públicos, que serão apresentadas a seguir. Assim, a EA se caracteriza por propiciar as pessoas uma compreensão crítica e global do ambiente, por meio da formação de valores e atitudes conscientes no trato com o meio ambiente. Sobre isso, Brasil (1999) determina que:

Art. 1 - Entendem-se por educação ambiental os processos por meio dos quais o indivíduo e a coletividade constroem valores sociais, conhecimentos, habilidades, atitudes e competências voltadas para a conservação do meio ambiente, bem de uso comum do povo, essencial à sadia qualidade de vida e sua sustentabilidade. (BRASIL, Lei no 9795/1998).

Conforme Dias (1998), o Conselho Nacional do Meio Ambiente (CONAMA), definiu a EA como um processo de formação e informação, orientado para o desenvolvimento da consciência crítica sobre as questões ambientais, e de atividades que levam a participação das comunidades na preservação do meio ambiente. Para Reis (2008), a EA deve tratar dos valores, da necessidade de promover mudanças de comportamentos, de responsabilidade, participação e cidadania. Diante disso, a EA se apresenta como uma forma de evitar possíveis danos ao meio ambiente, a partir da busca de uma nova conduta da sociedade com

\footnotetext{
${ }^{1}$ As escolas foram escolhidas por trabalharem a educação ambiental em sua grade curricular e apresentarem em sua metodologia alguns traços que comprovam a utilização da pedagogia tradicional, com ênfase na educação ambiental conservadora.
} 
relação as questões ambientais.

A EA tem como objetivo principal a conscientização dos cidadãos sobre as condições socioambientais, podendo assim tomar decisões favoráveis a manutenção do planeta. Sobre essa questão, Fonseca (2009) comenta que a EA se propõe a formar cidadãos conscientes, capazes de tomar decisões incidentes sobre a realidade socioambiental, de forma comprometida com a vida do planeta. (FONSECA, 2009, p. 91).

De acordo com Brasil (1999), que implementa a Política Nacional de EA, declara que a EA na educação escolar, deve estar presente e ser desenvolvida no âmbito dos currículos das instituições de ensino públicas e privadas. Segundo Fonseca (2009), a EA é trabalhada em âmbito formal, nas escolas, se encaixando nos Parâmetros Curriculares Nacionais (PCN) e na lei de diretrizes e bases. No âmbito informal, a partir dos meios de comunicação de massa, que busca a compreensão dos problemas ambientais e a sensibilização para a preservação da natureza.

A regulamentação das práticas educativas relacionadas a EA no país, é feita pelos PCN, que foram implementados no Brasil em 1998. De acordo com BRASIL (1998), os PCN propõem que a EA seja trabalhada nas escolares de modo transversal, contínuo e permanente em todas as disciplinas e não como disciplina específica ou dentro de apenas uma área do conhecimento, pois necessita dos conhecimentos relativos de várias áreas do saber.

A EA deve ser trabalhada de forma transversal, envolvendo várias disciplinas e com o aprendizado de forma dinâmica, pautado na construção de valores. Sobre essa questão, Fonseca (2009) comenta que:

Seja ou não formal, a educação (ambiental) demanda um enfoque interdisciplinar, uma perspectiva global e equilibrada, que se acha na cooperação/interação entre todas as disciplinas ou campos de atuação do tema, sendo importante a abordagem dos seus aspectos sociais, matemáticos, históricos, geográficos, das línguas, artes e filosofia. (FONSECA, 2009, p.94)

Para Reigota (1998), a EA não deve se fundamentar em conteúdo específicos, mas pelo fato de não existir conteúdo único, deve se adaptar a faixa etária dos discentes e ao contexto educativo em que se processam as atividades. Enquanto, de acordo com Fonseca (2009), a perspectiva ambiental na educação deve abordar os vários agentes que fazem parte da natureza, além disso, deve-se tentar entender a natureza como um todo.

O desenvolvimento das atividades relacionadas ao meio ambiente deve levar em consideração as diversas maneiras de assimilar as relações entre sociedade e natureza. Sobre essa questão, Fonseca (2009), afirma que

O enfoque da dimensão ambiental da educação significa a retomada da discussão sobre a inserção do processo educativo como parte integrante do ambiente, ou seja, vislumbrar um processo educacional que leve em conta as diversas formas de relações sociedade/natureza. (FONSECA, 2009, p.120)

A inclusão da EA no currículo escolar representa uma quebra das características históricas da escola e marca um novo momento na educação do país, que possibilita interligar os diversos campos do conhecimento e a criação de novas técnicas e metodologias de ensino. Neste sentido, Fonseca (2009), afirma que:

A inserção da Educação (Ambiental) na grade curricular inaugura um processo de ruptura com a caracterização histórica da escola, na medida em que possibilita o diálogo de saberes entre os mais diversos campos do conhecimento, constituindo-se desta forma, num fértil terreno para novas práticas educacionais. (FONSECA, 2009, p.92). 
Entretanto, mesmo não seguindo a política nacional, o ensino de EA é trabalhado sob a perspectiva da pedagogia tradicional e envolve aspectos diferentes do enfoque dinâmico, interdisciplinar e participativo adotado para se trabalhar EA. sendo trabalhada a partir da pedagogia tradicional em muitas instituições escolares. Assim, é necessário apontar as principais características apresentadas por essa perspectiva metodológica de ensino.

A pedagogia tradicional coloca o professor como detentor de todo o conhecimento que é repassado aos alunos, expondo os conteúdos, utilizando o recurso da oralidade. Sobre essa questão, Libâneo (1994), discorre que

A pedagogia tradicional, a didática é uma disciplina normativa, um conjunto de princípios e regras que regulam o ensino. A atividade é centrada no professor que expõe e interpreta a matéria. As vezes são utilizados meios como a apresentação de objetos, ilustrações, exemplos, mas o meio principal é a palavra, a exposição oral. (LIBÂNEO, 1994, p.64).

Na pedagogia tradicional, o aluno é um mero reprodutor do conhecimento, apenas observa a transmissão do conhecimento do professor e os exercícios praticados são apenas de repetição e memorização. Libâneo (1994), argumenta que

Supõe se que ouvindo e fazendo exercícios repetitivos, os alunos gravam a matéria para depois reproduzila, seja nas interrogações do professor, seja através de provas. Para isso é importante que o aluno 'preste atenção', porque ouvindo facilita-se o registro do que se transmite na memória. (LIBÂNEO, 1994, p.64)

Para Guimarães (2007), a EA trabalhada sobre a perspectiva tradicional é conhecida como conservadora, na qual, para a melhoria das condições ambientais se dará pela transformação de cada indivíduo. A EA conservadora ainda está presente em instituições escolares, por estar atrelada a um modelo educacional pautado na transformação individual de cada indivíduo, deixando de lado práticas pedagógicas coletivas no desenvolvimento de condições ambientais favoráveis. Sobre essa questão, Guimarães (2006), afirma que

Essa educação ambiental se faz conservadora por estar presa á armadilha paradigmática, entre outras múltiplas determinações deste modelo hegemônico; por voltar-se para um processo educacional focado no indivíduo e na transformação de seu comportamento; por não vincular e perceber práticas educativas como uma intervenção individual e coletiva no processo de transformações socioambientais. (GUIMARÃES, 2006, p. 26).

Na EA conservadora é priorizado o lado cognitivo do processo pedagógico, quando o entendimento dos problemas ambientais e a mudança de atitudes relacionadas ao meio ambiente se dará pela transmissão de conhecimento. Sobre essa questão, Guimarães (2004), discorre que

Desta forma a Educação Ambiental Conservadora tende, refletindo os paradigmas da sociedade moderna, a privilegiar ou promover: o aspecto cognitivo do processo pedagógico, acreditando que transmitindo o conhecimento correto fará com que o indivíduo compreenda a problemática ambiental e que isso vá transformar seu comportamento e a sociedade; (GUIMARÃES, 2004, p. 27).

Para Guimarães (2004) na abordagem conservadora, a racionalidade sobrepõe a emoção, a disciplinaridade supera a transdisciplinaridade, o individualismo supera a coletividade e a abordagem local é totalmente desvinculada da global. A partir da organização da concepção de todos os autores que discutem sobre 
os assuntos relacionados ao tema da pesquisa, foi possível construir um arcabouço teórico que serviu como base para a análise das informações e a construção desta pesquisa.

\section{PERCURSO METODOLÓGICO}

Para a construção desta pesquisa foi necessário construir um arcabouço de informações para, assim, conseguir alcançar os objetivos. Diante disso, para a análise, comprovação das questões levantadas e a construção deste artigo, foram utilizados os seguintes procedimentos metodológicos.

Levantamento bibliográfico, buscando por leituras de autores que possibilitam a compreensão das temáticas abordadas na construção deste trabalho que serviram de base teórica para a sua construção do texto. As temáticas abordadas neste trabalho são: conceito de EA, a inserção da EA no ensino e a pedagogia tradicional. Os autores que serviram como aporte teórico são: Bogdan \& Biklen (2003); b) Dias (1998); c) Fonseca (2009); d) Guimarães (2004); e) Libâneo (1994) f) Reigota (1998) e g) Reis (2008), entre outros.

Levantamento de documentos legais, a leitura e análise dos documentos relacionados ao tema têm como finalidade compreender como uma legislação é estruturada e a forma na qual é executada. Nesta pesquisa, o primeiro documento estudado foi a lei no 9.795 de 27 / abril de 1999, que institui a política de EA no Brasil, sendo analisado a estruturação e o funcionamento da EA no ensino básico do país.

O segundo documento investigado foi a resolução $n^{\circ} 2$, de 15 de junho de 2012, que serviu como base para o entendimento sobre como se estabelece as diretrizes curriculares nacionais para a EA. O terceiro documento explorado foram os PCN para meio ambiente, instituído em1997, que relata como e quais os conteúdos relacionados a EA são trabalhados nas escolas do país.

Trabalho de campo, a investigação in loco ocorreu em duas instituições escolares que trabalham a EA a partir da perspectiva tradicional de ensino, proporcionando uma análise comparativa sobre o currículo das instituições para EA e análise do conhecimento dos discentes referente a esta temática.

A escola A está localizada no Bairro Conjunto Esperança e conta com os níveis de ensino infantil, fundamental e médio e considera implantar no seu ensino a pedagogia tradicional. A escola $\mathbf{B}$ se localiza no bairro Bonsucesso, tendo na escola as etapas de ensino infantil, fundamental e médio, além de declarar que a metodologia de ensino utilizada na escola está ligada a pedagogia tradicional. A figura 1 mostra a localização das duas escolas nas quais foram realizados o trabalho de campo para a obtenção dos dados que responda as questões levantadas e os objetivos da pesquisa. 
Figura 1 - Localização das Escolas - campo

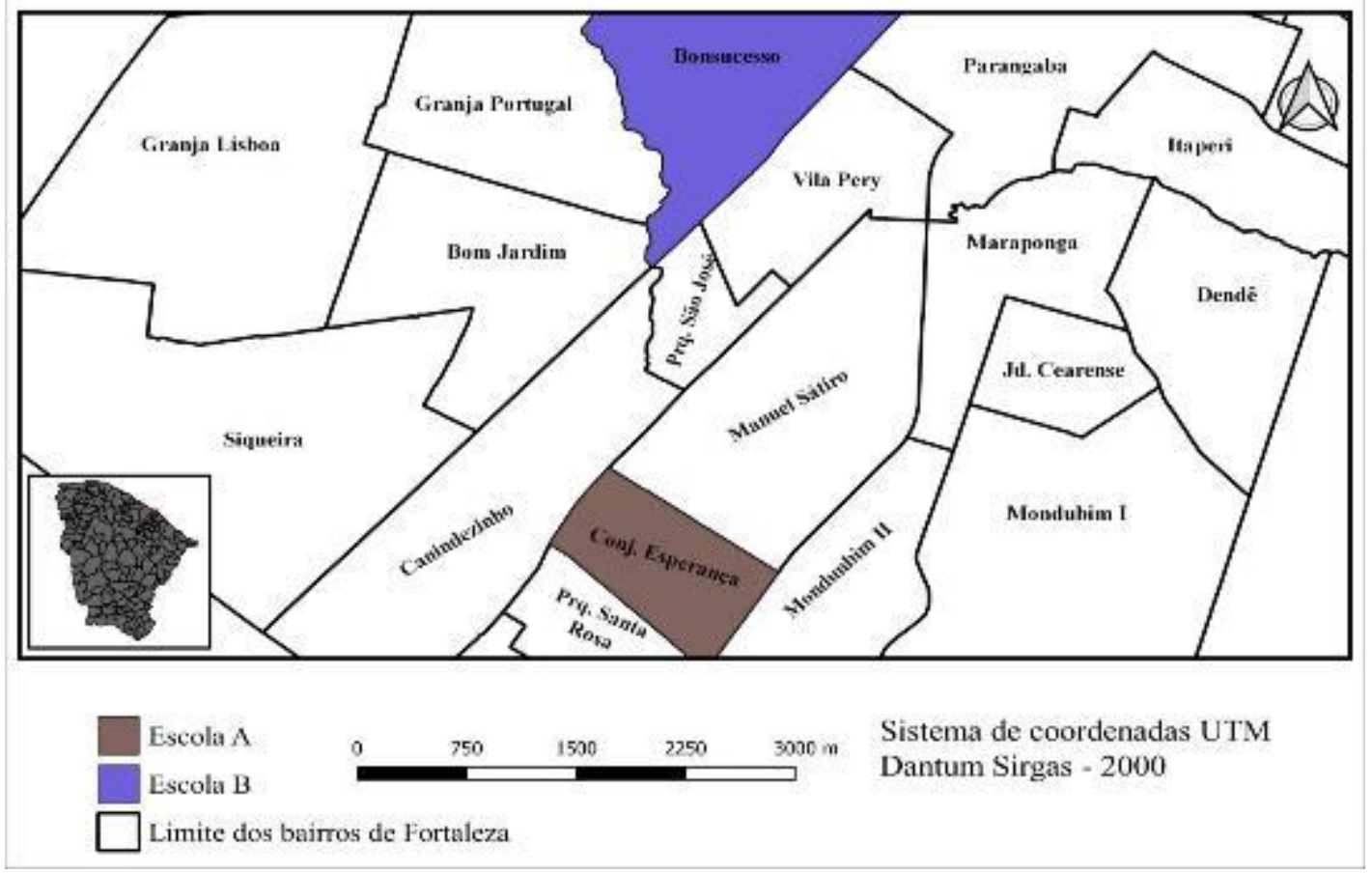

Fonte: Elaborado pelos Autores (2018).

Para a coleta de informações em campo, foi realizada a aplicação de um questionário específico com os alunos de uma turma do $9^{\circ}$ ano, do ensino fundamental II das escolas. Ao coletar todas as informações a partir da leitura dos autores e documentos relacionados ao tema, a realização do trabalho de campo e a coleta dos dados, além das reuniões de orientação, foram analisadas as informações extraídas em todas as etapas da pesquisa, para se chegar a uma melhor compreensão do tema e averiguar os resultados da pesquisa.

Nesta pesquisa foi adotada a abordagem qualitativa, pois, se propõe a estudar um aspecto da realidade, sem quantificar os dados, centrando na explicação e compreensão da dinâmica das relações sociais. De acordo com Triviños (1987), a pesquisa qualitativa trabalha os dados buscando o seu significado, tendo como base a percepção do fenômeno dentro do seu contexto.

Segundo Bogdan \& Biklen (2003), a pesquisa qualitativa envolve cinco características básicas que montam esse tipo de estudo, tais como: o ambiente natural, como sua fonte direta de dados e o pesquisador como principal instrumento, havendo um contato direto entre ambiente natural e pesquisador, os dados gerados predominantemente descritivos, a preocupação do estudo maior que o produto, o significado que as pessoas dão as coisas e a sua vida foram foco de atenção do pesquisador, além da análise dos dados seguir um processo indutivo.

Todos os procedimentos metodológicos foram de vital importância para se chegar as informações necessárias para a construção deste trabalho e o método científico adotado para a realização da pesquisa, que foi possível definir a partir da identificação do tipo de estudo realizado para cumprir os objetivos da pesquisa.

\section{RESULTADOS E DISCUSSÕES}

Ao longo desse tópico, serão explanados os dados obtidos relacionados ao conhecimento dos 
discentes acerca das questões ambientais, que envolve questões sobre a relevância da EA aos conceitos relacionados ao meio ambiente e sobre o ensino da temática ambiental nos colégios onde a pesquisa de campo foram realizadas. Foram entrevistados vinte alunos do $9^{\circ}$ ano do ensino fundamental na Escola A e 23 discentes do $9^{\circ}$ ano do ensino fundamental na Escola B. A figura 2, demonstra o conhecimento dos alunos sobre EA na Escola A. Foi constatado que 70\% dos alunos já ouviram falar a respeito de EA, enquanto na Escola B, 80\% dos discentes conheciam o tema.

Figura 2 - Conhecimento atual dos alunos sobre EA

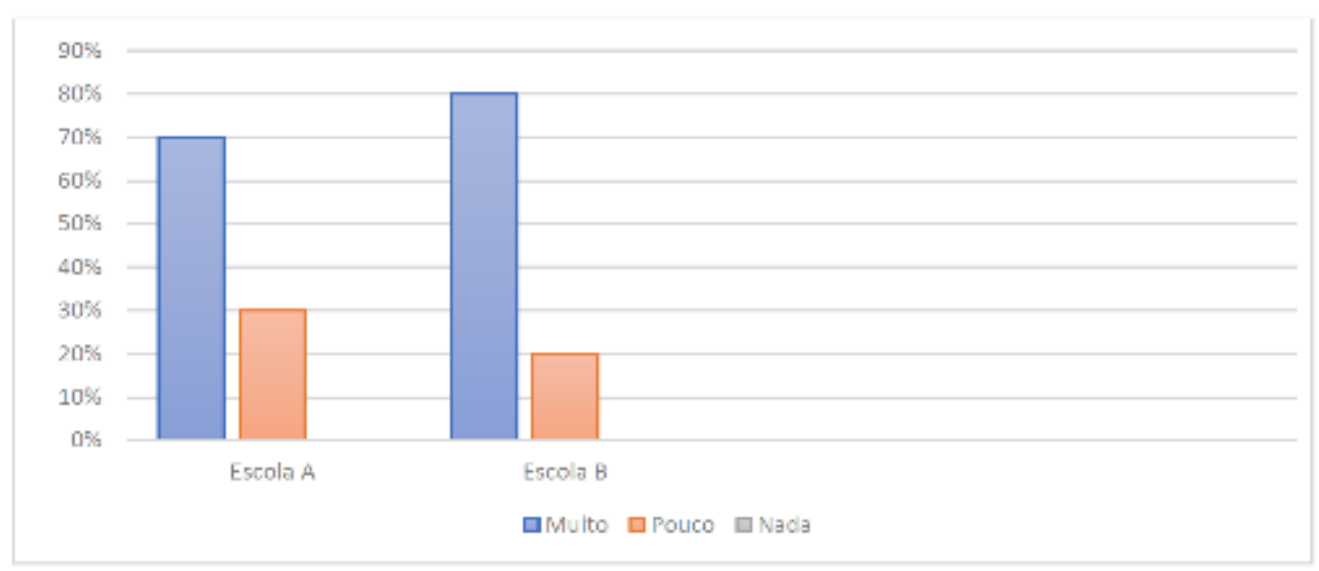

Fonte: Elaborado pelos Autores (2018).

Levando em consideração o conhecimento dos alunos em relação a EA, constatou-se que os alunos das duas instituições escolares têm pouco conhecimento sobre as questões ambientais, em decorrência da forma como a temática ambiental é trabalhada nas escolas, de forma anual ou semestral, com aulas expositivas, que não desenvolvem nos discentes aspectos fundamentais como a criticidade e a criatividade.

No que concerne a importância de entender a proposta da EA para a conservação do meio ambiente, 100\% dos alunos da Escola A consideram muito importante entender a proposta da EA, enquanto na Escola B, $80 \%$ dos discentes considera muito significativo, 19\% acham pouco relevante e 1\% diz que não é necessário entender a proposta da EA para a melhoria do meio ambiente.

Diante da abordagem fraca sobre EA nas escolas, pôde se notar que a maioria dos alunos das duas instituições escolares consideram importante entender a proposta da temática relacionada ao meio ambiente, por se tratar de um tema atual e está ligado as questões ambientais do país.

Como se percebe na figura 3, quanto ao acesso dos discentes a informações sobre EA, na Escola $\mathbf{A}$ os principais acessos dos alunos aos conteúdos relacionados ao meio ambiente são: Livros 25\%, Internet $80 \%$, Jornais/revistas 20\%, Escola 65\%, Televisão 90\% e Palestras 25\%. Entretanto, na Escola B, os alunos têm acesso as questões ambientais por meio de Livros 35\%, Internet $92 \%$, Jornais/revistas 27\%, Escola 79\%, Televisão 65\% e Palestras 8\%. É relevante informar que os estudantes poderiam citar vários meios de comunicação em suas respostas. 
Figura 3 - Acesso dos discentes as informações sobre o meio ambiente

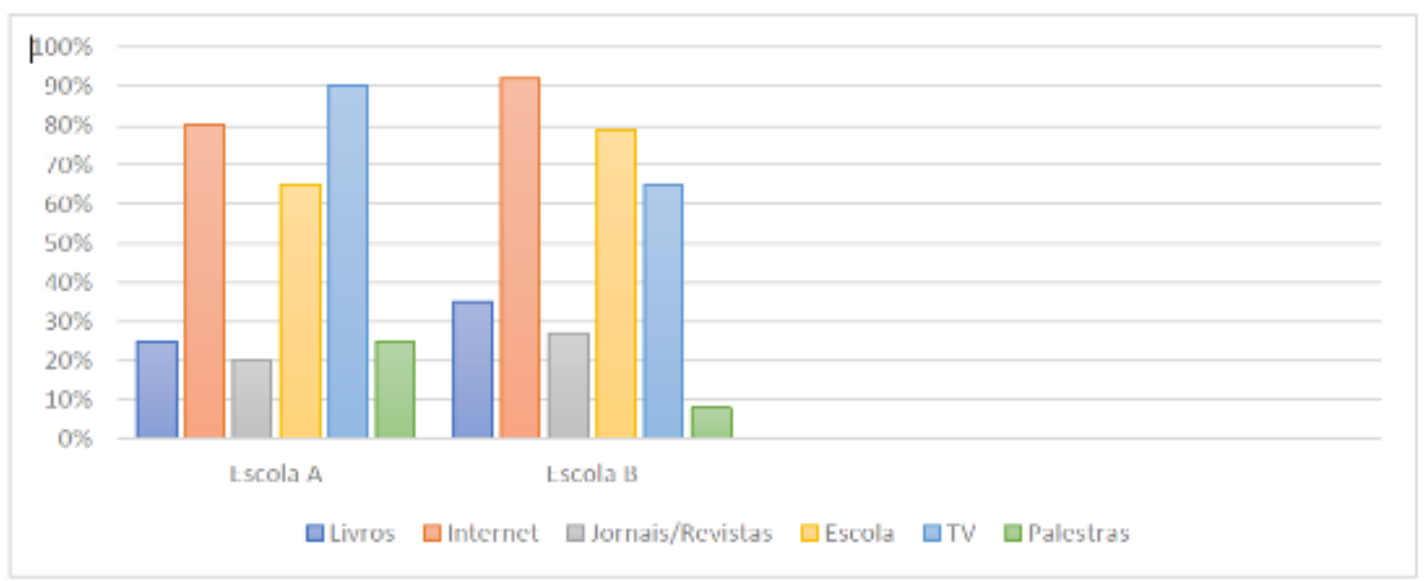

Fonte: Elaborado pelos Autores (2018).

Levando em consideração a opinião dos discentes sobre o acesso das informações sobre EA, de acordo com os PCN, a escola deveria ser a principal fonte de informações e formação dos alunos sobre a temática, visto que é no ambiente escolar que o estudante tem condições de construir seu conhecimento sobre o tema por meio da criatividade, desenvolvendo ações sobre o tema. A escola é um espaço excelente para se trabalhar EA, uma vez que desperte a criatividade dos discentes. Sobre esse ponto Reigota (1998, p. 24) afirma que "A escola é um dos locais privilegiados para a realização da Educação Aambiental, desde que dê oportunidade a criatividade".

Como indica a figura 4, no que diz respeito ao interesse dos alunos por estudar EA, na Escola $\mathbf{A}$, $25 \%$ tem muito interesse em conhecer as questões ambientais, $70 \%$ tem pouco interesse e $5 \%$ não tem nenhum interesse em estudar a temática. Ao levar esse questionamento para a Escola $\mathbf{B}$, percebeu se que 18\% dos discentes tem muito interesse em estudar EA, 70\% tem pouco interesse em aprender os conteúdos sobre o meio ambiente e $12 \%$ dos alunos dizem não ter nenhum interesse em ter alguma instrução sobre essa temática.

Figura 4 - Interesse dos alunos por estudar EA

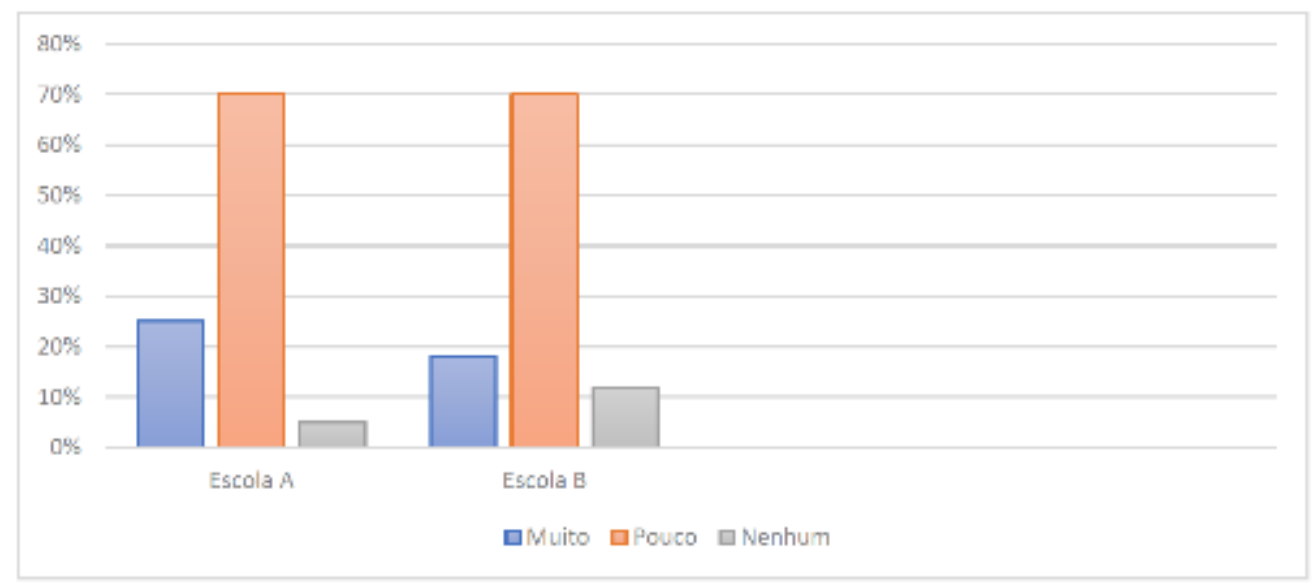

Fonte: Elaborado pelos Autores (2018).

Tendo em vista o mínimo interesse dos alunos das duas instituições escolares em estudar EA, foi 
constatado que esse problema se dá pela forma como a EA é abordada nas escolas, raramente e que não envolve todas as áreas do conhecimento e toda a comunidade escolar, propondo uma abordagem conservadora.

Ao abordar as perguntas sobre os conceitos específicos relacionados ao meio ambiente, questionando os discentes dos dois colégios sobre o conceito de sustentabilidade, observou se que $80 \%$ e $92 \%$ dos alunos do $9^{\circ}$ ano das Escolas $\mathbf{A}$ e $\mathbf{B}$, respectivamente, responderam que esse conceito está atrelado a utilização dos recursos do meio ambiente pelo ser humano, de forma que não comprometa as gerações futuras.

Ao indagar sobre a concepção dos alunos das instituições sobre EA, verificou se que $70 \%$ e $80 \%$ das Escolas A e B, nessa ordem, que a EA se caracteriza por propiciar as pessoas uma compreensão crítica e global do ambiente, por meio da formação de valores e atitudes conscientes no trato com o meio ambiente, enquanto 30\% e 20\% dos alunos das mesmas instituições apontam que a EA é apenas um assunto que traz um panorama sobre a situação do meio ambiente.

Foi questionado aos estudantes das duas escolas, sobre qual era a finalidade da EA, 40\% e 9\% das Escolas A e B, na devida ordem, que a finalidade da EA é somente separar, coletar e reutilizar o lixo de forma correta, enquanto $60 \%$ e $91 \%$ das mesmas escolas, afirmaram que o objetivo é proporcionar a todos a possibilidade de adquirir conhecimentos, o sentido dos valores, o interesse ativo e as atitudes necessárias para proteger e melhorar o ambiente.

No ponto de vista de 50\% e 87\% dos alunos das instituições de ensino A e B nessa ordem, afirmaram que as pessoas sabem que destroem o meio ambiente e ainda relataram que as principais ações humanas que causam modificações no ambiente natural do país são: Jogar lixo nas ruas e rios, desperdício d água, queima de lixo na rua, desmatamento, poluição de água e a poluição do ar com a emissão de gases tóxicos e a falta de saneamento básico.

Quando se trata do conhecimento dos educandos em relação aos temas relacionados ao meio ambiente, percebe-se que os estudantes ainda têm uma visão reduzida sobre as questões ambientais. Vale ressaltar que os estudantes ainda se confundem e tem interpretações diversas sobre essas temáticas, além da grande dificuldade em discorrer sobre o tema, mesmo que seja para identificar os problemas ambientais que estão no seu cotidiano.

Essa dificuldade dos discentes com relação ao assunto, ocorre pela forma como as escolas trabalham a temática, sem despertar a criticidade e a capacidade de interpretar e resolver as questões referentes ao ambiente, aliado a falta de capacitação dos profissionais do ensino para abordar esse tema, comprovando a presença da abordagem conservadora da EA nas escolas onde a pesquisa se realizou.

Ao investigar sobre o ensino de EA nas duas escolas, foi indagado aos alunos em qual frequência os assuntos relacionados a conservação do ambiente são tratados em sala de aula. No entendimento dos educandos da Escola A, 15\% afirmaram que sempre viam a temática ambiental em sala de aula, já 85\% admitiram que a EA é trabalhada raramente no ambiente de ensino. Na Escola B, a EA sempre foi abordada na avaliação de 30\% dos discentes, $5 \%$ declaram nunca ter visto nada relacionado ao meio ambiente durante as aulas e 65\% disseram que a conscientização ambiental é abordada raramente.

De acordo com 85\% e 87\% dos alunos do $9^{\circ}$ ano entrevistados nas Escolas $\mathbf{A}$ e $\mathbf{B}$, respectivamente, afirmaram que as aulas e ações realizadas pelas duas escolas referentes a EA, contribuíram para a sua conscientização sobre as problemáticas do ambiente.

Essas poucas ações construídas sobre o tema ambiental, limitando a trabalhar EA em sala de aula, na qual os conhecimentos são adquiridos de forma individual, confirma a presença da EA tal conservadora 
nessas instituições escolares. Sobre esse assunto, Guimarães (2007), relata que a EA trabalhada sobre a perspectiva tradicional é conhecida como conservadora, na qual, para a melhoria das condições ambientais se dará pela transformação de cada indivíduo. É necessário que se cumpra a política nacional e os PCN para EA e elabore ações que sejam durante todo o ano letivo, integre todas as áreas do conhecimento, que envolva e faça com que os alunos construam suas concepções sobre essa temática.

Como mostrado na figura 5, 80 \% dos alunos da Escola $\mathbf{A}$ afirmaram que a formação sobre EA na escola é de muito importante para a vida deles, que em suas visões, contribui para ajudar a conscientizar sobre o ambiente, aprender a cuidar do planeta, para que no futuro as pessoas saibam cuidar do ambiente natural e melhorar suas condições, entretanto, $20 \%$ diz que a formação não é importante.

Figura 5 - Consideração sobre a importância da formação em EA na escola

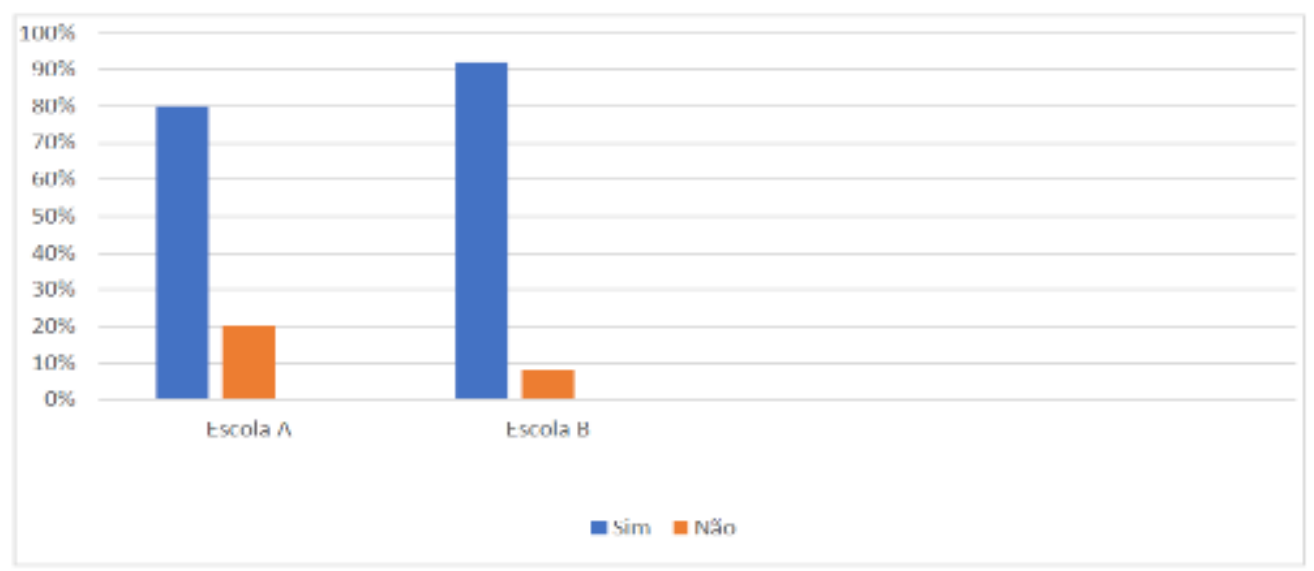

Fonte: Elaborado pelos Autores (2018).

Já na Escola B, 92\% dos alunos consideram que a instrução sobre EA é importante, pois coopera para informar sobre a situação atual do ambiente; explica as questões relacionadas ao tema, aprende e se conscientizar mais sobre o assunto, aprenderem a conservar o meio ambiente e assim deixar um planeta melhor para as gerações futuras, além de cuidar e respeitar o ambiente onde se vive, porém, $8 \%$ afirma que a formação sobre a temática não é interessante e não contribui em nada para a sua vida.

Conforme a proposta da PNEA e dos PCN para a EA, é necessário que seja trabalhada em todas as disciplinas do currículo escola, não se restringindo apenas algumas disciplinas, a partir de ações e projetos contínuos que envolva e desenvolva nos estudantes a compreensão dos problemas do seu cotidiano para possibilitar o entendimento dos problemas globais. Essa visão dos educados condizem com as informações relatadas por gestores e profissionais de educação das escolas, além disso, comprova mais ainda a existência do ensino de EA a partir de uma abordagem conservadora nos colégios investigados.

\section{CONSIDERAÇÕES FINAIS}

Neste trabalho, tendo como base o trabalho de campo realizado em duas escolas, foram abordadas as perspectivas dos discentes de escolas tidas como tradicionais sobre a EA. A realização deste estudo possibilitou a comunidade acadêmica, a sociedade e aos estudiosos desta área, a possibilidade de conhecer a perspectiva dos alunos do ensino fundamental II de escolas que se declaram tradicionais sobra a EA, contribuindo para se chegar a novas ideias sobre o tema, além da realização pessoal em está trabalhando com o 
ensino de EA e ter a oportunidade de responder as inquietações sobre o assunto, podendo assim continuar a trabalhar nessa temática.

Ao analisar o conhecimento dos discentes, ficou perceptível que a EA é pouco relevante para os alunos, tendo uma visão limitada dessa temática e pouco interesse em estudar as questões ambientais, além da dificuldade em escrever sobre o tema. Vale ressaltar que na concepção dos alunos, a EA é abordada raramente em sala de aula. Com isso, pode se afirmar que um dos motivos pela falta de interesse e conhecimento dos estudantes sobre a temática, é resultado de como a EA é desenvolvida nas escolas onde a pesquisa foi realizada.

A construção deste trabalho teve como finalidade aumentar o nível de conhecimento e aprofundamento do pesquisador sobre o tema, a partir da possibilidade de conhecer de perto e assim compreender melhor a temática trabalhada, deixando aberta um leque de oportunidades para evolução desta pesquisa, além do prazer em desenvolver uma pesquisa acadêmica que possa contribuir para futuros estudos com assuntos relacionados a este trabalho.

\section{REFERÊNCIAS}

BRASIL. Lei $n^{\circ} .9795$ de 27 de abril de 1999. Dispõe sobre a educação ambiental, institui a Política Nacional de Educação Ambiental e dá outras providências. Disponível em: <http://www.planalto.gov.br/ccivil_03/Leis/L9795.htm>. Acesso em: 20 set 2017.

BOGDAN, R. S.; BIKEN, S. Investigação qualitativa em educação: uma introdução à teoria e aos métodos. 12.ed. Porto: Porto, 2003.

DIAS, Genebaldo Freire. Educação Ambiental: princípios e práticas. 5. ed. São Paulo: Gaia. 1998

FONSECA, Valter Machado da. A educação ambiental na escola pública: Entrelaçando saberes, unificando conteúdo. São Paulo/SP: Biblioteca 24 horas, 2009. v. 1. 297p.

GUIMARÃES, Mauro. A formação de educadores ambientais. Campinas, SP: Papirus, 2007.

. Armadilha pragmática na educação ambiental. In: LOUREIRO, Carlos (Org.), LAYRARGUES, Philippe (Org.) e CASTRO, Ronaldo (Org.). Pensamento complexo, dialética e educação ambiental. São Paulo: Cortez, 2006.

. Educação Ambiental Crítica. In: Philippe Pomier Layrargues (coord.). Identidades da educação ambiental brasileira / Ministério do Meio Ambiente - Brasília: Ministério do Meio Ambiente, 2004.

LIBÂNEO, José Carlos. Didática. São Paulo: Cortez, 1994.

REIS, Marília de Campos T. Educação Ambiental: Natureza, razão e história. 2. ed. São Paulo. Autores associados. 2008

REIGOTA, Marcos. O que é educação ambiental. São Paulo: Brasiliense. 1998.

TRIVIÑOS, Augusto N. S. Introdução à pesquisa em ciências sociais: a pesquisa qualitativa em educação. São Paulo: Atlas, 1987. 